\title{
Anthropometric parameters in relation to glycaemic status and lipid profile in a multi-ethnic sample in Italy
}

\author{
Emanuela Gualdi-Russo ${ }^{1}$, Luciana Zaccagni ${ }^{1, *}$, Giovanna V Dallari ${ }^{2}$ and Stefania Toselli ${ }^{3}$ \\ 'Department of Biomedical and Specialty Surgical Sciences, Ferrara University, Corso Ercole I D'Este no. 32, \\ University of Ferrara, 44121 Ferrara, Italy: ${ }^{2}$ Bologna Public Health Service, Bologna, Italy: ${ }^{3}$ Department of \\ Biomedical and Neuromotor Science, Bologna University, Bologna, Italy
}

Submitted 23 July 2013: Final revision received 13 December 2013: Accepted 14 March 2014: First published online 24 April 2014

\begin{abstract}
Objective: To examine the health status of ethnic minorities in Italy. Furthermore, we aimed to assess the association between anthropometric and blood parameters connected with health status.

Design: A cross-sectional study. Anthropometric data were collected by direct measurements and blood glucose, total cholesterol and TAG were analysed.

Setting: Bologna, northern Italy.

Subjects: A multi-ethnic sample of adult immigrants and Roma.

Results: Significant correlations between anthropometric and blood parameters were found. Among the ethnic groups, Roma males had the highest values of glucose, total cholesterol and TAG. In the females the situation was more balanced among ethnic groups.

Conclusions: The data from this survey indicate that poor health status is a very common problem among ethnic groups living in Italy, especially the Roma. The use of anthropometric parameters as rapid indicators of health status in screenings of a large number of subjects could be an effective and cheap method to provide preliminary indications on individuals or ethnic groups at greater risk of poor health.
\end{abstract}

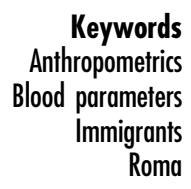

Risk factors for CVD and diabetes, such as dyslipidaemia and elevated plasma glucose levels, are believed to be associated with anthropometric characteristics ${ }^{(1-4)}$. In particular, it has been suggested that general fatness and central obesity influence blood parameters such as TAG and glycaemia ${ }^{(5)}$; central obesity with increased waist circumference (WC) has been defined as the essential component for metabolic syndrome and one of the most important CVD risk factors ${ }^{(6-8)}$.

Migrants are a high-risk population for the development of metabolic syndrome owing to the substantial changes in their lifestyle ${ }^{(9,10)}$. Strong influences of the host country have been found on dietary habits, stress levels, social conditions and ultimately the health of immigrants ${ }^{(11-14)}$. Moreover, different associations between obesity (especially abdominal fat) and CVD risk factors have been observed in different ethnic groups ${ }^{(15-17)}$.

Immigration has reached high levels in Italy: according to ISTAT ${ }^{(18)}$, resident foreigners in Italy totalled 4570317 at 1 January 2011 and the proportion of foreign citizens in the total resident population (Italians and foreigners) was $7 \cdot 5 \%$. Nevertheless, too little is known about the general health status of the immigrants and this problem is enhanced in the frequent cases of clandestine people.
The present research began in 2000 as part of a general project funded by the Italian Health Ministry aimed at avoiding health disparities of the immigrant population living in Italy. The study is continuing as part of a European project on immigration (EUNAM) to evaluate health status, prevent disease and provide free health-care and services. As we previously identified diverse CVD risk profiles in different ethnic groups from the same immigrant sample ${ }^{(19)}$, we wished to determine if these findings extended to glycaemic and lipid disorders.

Therefore, the aims of the present study were to: (i) evaluate the health status of Italian immigrants and Roma by means of blood indicators; (ii) determine the association between anthropometric traits and blood indicators in people with different ethnic backgrounds; and (iii) thus find a rapid and non-invasive method for health screening of large samples of subjects.

\section{Methods}

\section{Design and sampling}

The target population consisted of adult immigrants and Roma living in Bologna (northern Italy). Among the 
immigrants living in the Bologna centres who were invited to take part in the study after various meetings held in immigrant centres to inform potential participants about the study, 401 people agreed to participate. The recruited individuals underwent a physical examination by physicians and an anthropometric survey in several health clinics in Bologna. More detailed information on the recruitment procedure, inclusion criteria, methods and locations have been reported previously ${ }^{(19)}$

From this initial sample, data on a total of $301 \mathrm{immi-}$ grants, 229 men (forty-three Senegalese; seventeen Tunisians; 134 Moroccans; nine Kosovars; twenty-six Roma) and seventy-two women (twenty-one Moroccans; sixteen Kosovars; thirty-five Roma), were available for the present study. The mean age of the sample was $40 \cdot 1$ (SD 10.4) years for males and 35.2 (SD 12.5) years for females. The ethnicity (established on the basis of native country) and other personal data were collected during a preliminary interview.

The research complied with the principles of the Helsinki Declaration. All participants provided written informed consent before participating in the project, which was approved by the Italian Ministry of Health.

\section{Measures}

The following anthropometric traits were measured by expert anthropometrists using standard techniques and equipment ${ }^{(20)}$ : height, weight, relaxed arm circumference and triceps skinfold thickness, waist and hip circumferences (Senegalese group excepted, as explained in our previous study) ${ }^{(19)}$.

Height was measured in centimetres to the nearest $0.1 \mathrm{~cm}$ on a portable stadiometer. Weight was measured in kilograms to the nearest $0.1 \mathrm{~kg}$. Mid-upper arm circumference was measured to the nearest $0 \cdot 1 \mathrm{~cm}$ on the left side. Triceps skinfold thickness was measured to the nearest $0.1 \mathrm{~cm}$ with a Lange calliper at the same midpoint of the left upper arm. WC was measured to the nearest $0.1 \mathrm{~cm}$ at the level of the minimum circumference of the torso of the standing participant at the end of a normal expiration. Hip circumference (HC) was measured to the nearest $0.1 \mathrm{~cm}$ at the level of the greatest gluteal protuberance, as observed in lateral view.

BMI was computed as weight in kilograms divided by the square of height in metres. Waist-to-hip ratio (WHR) was calculated as the ratio of WC to HC. Waist-to-stature ratio (WSR) was calculated as WC divided by height. Total upper-arm area (TUA), upper-arm muscle area (UMA), upper-arm fat area (UFA) and arm fat index (AFI) of the upper arm were calculated following Frisancho's formulas ${ }^{(21)}$.

BMI cut-off points were BMI $\geq 25 \mathrm{~kg} / \mathrm{m}^{2}$ for overweight and $\mathrm{BMI} \geq 30 \mathrm{~kg} / \mathrm{m}^{2}$ for obesity, according to the $\mathrm{WHO}^{(22)}$. Similarly, cut-off points for abdominal fat distribution indicating increased health risk ${ }^{(23)}$ were WHR $\geq 1.00$ for men, WHR $\geq 0.85$ for women and WSR $\geq 0.5$ for both sexes.
Fasting blood samples were collected and concentrations of serum total cholesterol (TC), serum TAG and serum blood glucose (GLY) were determined using automated techniques in the laboratory of Maggiore Hospital, Bologna. This clinical laboratory used standard methods and met international quality control programmes. Cut-off values were $\mathrm{TC} \geq 200 \mathrm{mg} / \mathrm{dl}$ for increased TC, TAG $\geq 150$ $\mathrm{mg} / \mathrm{dl}$ for elevated TAG and GLY $\geq 100 \mathrm{mg} / \mathrm{dl}$ for elevated GLY (National Cholesterol Education Program) ${ }^{(24)}$.

\section{Statistical analysis}

Data are reported as means and standard deviations. Normality of variables was tested by the Shapiro-Wilk $W$ test. TAG was logarithmically transformed and GLY was transformed as the reciprocal of the value before performing statistical analyses (ANOVA, Tukey post hoc comparisons). Pearson's coefficients of correlation between blood parameters and anthropometric variables were determined within each sex. Regression analyses were performed with each blood trait as the dependent variable and WC, WSR and WHR as the independent variables.

All tests were conducted with $P$ set at 0.05 for significance using the STATISTICA statistical software package version 11.0 (2012).

\section{Results}

\section{General characteristics of immigrants and Roma}

The anthropometric and metabolic data for men and women are presented in Tables 1 and 2, respectively, stratified by ethnic background. There was a significant difference (ANOVA) among the five groups of men for height, BMI, WHR, WSR and TAG. For the three female groups, weight, arm, waist and hip circumferences, TUA and TC were significantly different. Statistical comparisons (Tukey's test) between single ethnic groups are reported at the bottom of the same tables.

Among the males, Senegalese were the tallest and had the lowest values of BMI, UFA and AFI. Senegalese also had the lowest TAG values. Roma men were the shortest, with the largest arm and waist circumferences, as well as the highest values of BMI, WHR, WSR and AFI. They also had the highest mean values of GLY, TC and TAG. Kosovars showed high values of BMI, arm and waist circumferences, triceps skinfold and AFI, as well as high TC and TAG values. The two centrality indices used in the present study were also high in Moroccans.

Among the females, Roma were the shortest and lightest, with the smallest arm, waist and hip circumferences, as well as the lowest values of BMI, WHR, WSR, TUA, UMA, UFA and AFI. However, they showed the highest values of TC and TAG. Kosovar women had the largest WC and HC, with the highest values of WSR, but the lowest values of GLY and TAG. Moroccan women were the tallest, with the highest weight and skinfold thickness values, as well as the 
Table 1 Characteristics of males stratified by ethnic group and compared by ANOVA; multi-ethnic sample of adult immigrants, Bologna, northern Italy

\begin{tabular}{|c|c|c|c|c|c|c|c|c|c|c|c|}
\hline \multirow[b]{2}{*}{ Characteristic } & \multicolumn{2}{|c|}{$\begin{array}{l}\text { Senegalese } \\
\quad(n 43)\end{array}$} & \multicolumn{2}{|c|}{$\begin{array}{l}\text { Tunisians } \\
\text { (n 17) }\end{array}$} & \multicolumn{2}{|c|}{$\begin{array}{l}\text { Moroccans } \\
\quad(n 134)\end{array}$} & \multicolumn{2}{|c|}{$\begin{array}{c}\text { Kosovars } \\
(n 9)\end{array}$} & \multicolumn{2}{|c|}{$\begin{array}{l}\text { Roma } \\
(n 26)\end{array}$} & \multirow[b]{2}{*}{$P$ value } \\
\hline & Mean & SD & Mean & $\mathrm{SD}$ & Mean & SD & Mean & $\mathrm{SD}$ & Mean & SD & \\
\hline Height (cm) & 178.5 & $7 \cdot 1$ & $172 \cdot 7$ & 4.9 & $171 \cdot 7$ & $6 \cdot 4$ & $169 \cdot 5$ & 3.5 & $167 \cdot 0$ & $5 \cdot 1$ & $<0.001$ \\
\hline Weight (kg) & $73 \cdot 1$ & $12 \cdot 0$ & 74.4 & $11 \cdot 6$ & $73 \cdot 0$ & $11 \cdot 3$ & $80 \cdot 1$ & 21.4 & $77 \cdot 8$ & $17 \cdot 4$ & 0.2796 \\
\hline BMI $\left(\mathrm{kg} / \mathrm{m}^{2}\right)$ & $22 \cdot 9$ & $3 \cdot 4$ & $25 \cdot 0$ & $4 \cdot 2$ & $24 \cdot 8$ & 3.5 & $27 \cdot 0$ & $7 \cdot 3$ & $28 \cdot 0$ & $6 \cdot 4$ & $<0.001$ \\
\hline Arm circumference $(\mathrm{cm})$ & $30 \cdot 5$ & $3 \cdot 1$ & $30 \cdot 5$ & 3.5 & $30 \cdot 3$ & 3.0 & $30 \cdot 7$ & $6 \cdot 2$ & $31 \cdot 0$ & 3.9 & 0.8926 \\
\hline WC (cm) & - & - & $88 \cdot 0$ & $10 \cdot 9$ & $90 \cdot 7$ & $10 \cdot 2$ & $91 \cdot 1$ & $19 \cdot 8$ & $96 \cdot 2$ & $15 \cdot 8$ & 0.1486 \\
\hline $\mathrm{HC}(\mathrm{cm})$ & - & - & $98 \cdot 2$ & $5 \cdot 6$ & $96 \cdot 5$ & $6 \cdot 8$ & $89 \cdot 4$ & $12 \cdot 8$ & $96 \cdot 9$ & $9 \cdot 2$ & 0.3051 \\
\hline WHR & - & - & 0.91 & 0.07 & 0.94 & 0.06 & 0.87 & 0.07 & 0.97 & 0.08 & 0.0081 \\
\hline WSR & - & - & 0.51 & 0.07 & 0.53 & 0.06 & 0.52 & 0.11 & 0.58 & 0.10 & 0.0126 \\
\hline Triceps skinfold (mm) & 8.9 & 3.7 & $9 \cdot 7$ & $4 \cdot 3$ & $9 \cdot 7$ & 3.7 & $11 \cdot 4$ & $7 \cdot 5$ & $11 \cdot 1$ & $4 \cdot 3$ & 0.2285 \\
\hline TUA $\left(\mathrm{cm}^{2}\right)$ & $74 \cdot 7$ & $15 \cdot 3$ & $75 \cdot 2$ & $17 \cdot 4$ & $73 \cdot 8$ & 14.4 & $77 \cdot 6$ & 30.6 & $77 \cdot 6$ & $20 \cdot 1$ & 0.8337 \\
\hline UMA $\left(\mathrm{cm}^{2}\right)$ & 61.4 & $11 \cdot 3$ & 60.6 & 11.9 & $59 \cdot 2$ & 10.5 & $59 \cdot 7$ & $17 \cdot 5$ & $61 \cdot 1$ & $15 \cdot 3$ & 0.8539 \\
\hline UFA $\left(\mathrm{cm}^{2}\right)^{\prime}$ & $13 \cdot 2$ & $6 \cdot 4$ & $14 \cdot 6$ & $7 \cdot 1$ & $14 \cdot 1$ & $6 \cdot 1$ & $18 \cdot 0$ & $14 \cdot 1$ & $16 \cdot 5$ & $7 \cdot 6$ & 0.2213 \\
\hline AFI (\%) & $17 \cdot 3$ & $5 \cdot 8$ & $18 \cdot 4$ & $6 \cdot 8$ & $18 \cdot 8$ & $6 \cdot 1$ & $20 \cdot 2$ & $10 \cdot 0$ & $21 \cdot 0$ & $7 \cdot 0$ & 0.2422 \\
\hline Serum GLY (mg/dl) & $90 \cdot 8$ & $11 \cdot 7$ & 89.5 & $18 \cdot 4$ & $96 \cdot 3$ & $27 \cdot 1$ & 89.9 & 8.8 & $101 \cdot 8$ & 33.9 & $0.2828 \dagger$ \\
\hline Serum TC $(\mathrm{mg} / \mathrm{dl})$ & $195 \cdot 3$ & 37.4 & $186 \cdot 8$ & $41 \cdot 8$ & 194.5 & 34.6 & 201.4 & 35.4 & $218 \cdot 3$ & $41 \cdot 3$ & 0.0753 \\
\hline Serum TAG (mg/dl) & 88.9 & $56 \cdot 6$ & $117 \cdot 9$ & $48 \cdot 3$ & $139 \cdot 2$ & 90.5 & $179 \cdot 7$ & $90 \cdot 8$ & $206 \cdot 5$ & $153 \cdot 9$ & $<0.001 \dagger$ \\
\hline
\end{tabular}

WC, waist circumference; HC, hip circumference; WHR, waist-to-hip ratio; WSR, waist-to-stature ratio; TUA, total upper-arm area; UMA, upper-arm muscle area; UFA, upper-arm fat area; AFI, arm fat index; GLY, blood glucose; TC, total cholesterol.

Note on Tukey's test between sub-samples: Senegalese $v$. Moroccans in height and TAG $(P<0.001)$; Senegalese $v$. Kosovars in height and TAG $(P<0.01)$; Senegalese $v$. Roma in height, BMI and TAG $(P<0.001)$; Moroccans $v$. Roma in height and BMI $(P<0.01)$ and WSR $(P<0.05)$; Roma $v$. Tunisians in height and WSR $(P<0.05)$; Kosovars $v$. Roma in WHR $(P<0.05)$. Other comparisons between groups were not significant.

†Computations were performed using normalized values.

Table 2 Characteristics of females stratified by ethnic group and compared by ANOVA; multi-ethnic sample of adult immigrants, Bologna, northern Italy

\begin{tabular}{|c|c|c|c|c|c|c|c|}
\hline \multirow[b]{2}{*}{ Characteristic } & \multicolumn{2}{|c|}{$\begin{array}{l}\text { Moroccans } \\
\quad(n 21)\end{array}$} & \multicolumn{2}{|c|}{$\begin{array}{c}\text { Kosovars } \\
(n 16)\end{array}$} & \multicolumn{2}{|c|}{$\begin{array}{l}\text { Roma } \\
(n \text { 35) }\end{array}$} & \multirow[b]{2}{*}{$P$ value } \\
\hline & Mean & SD & Mean & $\mathrm{SD}$ & Mean & SD & \\
\hline Height (cm) & 159.5 & $5 \cdot 8$ & $155 \cdot 2$ & $8 \cdot 0$ & $155 \cdot 2$ & $5 \cdot 7$ & 0.1159 \\
\hline Weight (kg) & $69 \cdot 9$ & 11.8 & $67 \cdot 0$ & 8.4 & 58.9 & $12 \cdot 7$ & 0.0126 \\
\hline $\operatorname{BMI}\left(\mathrm{kg} / \mathrm{m}^{2}\right)$ & $27 \cdot 6$ & 4.8 & 27.9 & $3 \cdot 9$ & 24.5 & $5 \cdot 4$ & 0.0588 \\
\hline Arm circumference $(\mathrm{cm})$ & 31.6 & 3.5 & $30 \cdot 4$ & 1.9 & 28.2 & 4.2 & 0.0359 \\
\hline WC (cm) & 87.5 & 11.4 & 94.5 & 7.5 & 80.5 & $13 \cdot 4$ & 0.0326 \\
\hline $\mathrm{HC}(\mathrm{cm})$ & 104.6 & $13 \cdot 2$ & 111.7 & $7 \cdot 0$ & $97 \cdot 6$ & $12 \cdot 5$ & 0.0365 \\
\hline WHR & 0.85 & 0.07 & 0.85 & 0.05 & 0.82 & 0.08 & 0.6131 \\
\hline WSR & 0.55 & 0.08 & 0.61 & 0.07 & 0.52 & 0.09 & 0.0636 \\
\hline Triceps skinfold (mm) & 13.7 & 7.5 & 11.9 & $5 \cdot 1$ & $10 \cdot 1$ & $6 \cdot 1$ & 0.2556 \\
\hline TUA $\left(\mathrm{cm}^{2}\right)$ & $80 \cdot 2$ & $17 \cdot 5$ & $73 \cdot 8$ & $9 \cdot 1$ & $65 \cdot 1$ & $17 \cdot 6$ & 0.0398 \\
\hline UMA $\left(\mathrm{cm}^{2}\right)$ & $60 \cdot 4$ & 18.5 & $56 \cdot 8$ & $6 \cdot 6$ & $51 \cdot 3$ & 13.0 & 0.1593 \\
\hline UFA $\left(\mathrm{cm}^{2}\right)^{\prime}$ & $19 \cdot 8$ & $10 \cdot 8$ & $17 \cdot 1$ & $7 \cdot 6$ & 13.9 & $10 \cdot 2$ & 0.2282 \\
\hline AFI (\%) & $25 \cdot 1$ & $12 \cdot 9$ & $22 \cdot 6$ & $7 \cdot 9$ & $20 \cdot 3$ & 9.5 & 0.4070 \\
\hline Serum GLY (mg/dl) & 93.6 & 23.2 & $81 \cdot 2$ & 11.4 & 85.4 & 9.9 & $0.0929 \dagger$ \\
\hline Serum TC $(\mathrm{mg} / \mathrm{dl})$ & $173 \cdot 4$ & $36 \cdot 0$ & $176 \cdot 4$ & $38 \cdot 8$ & $202 \cdot 5$ & $45 \cdot 8$ & 0.0422 \\
\hline Serum TAG (mg/dl) & 112.6 & $55 \cdot 8$ & 109.1 & $50 \cdot 1$ & $147 \cdot 0$ & $75 \cdot 7$ & $0.2014 \dagger$ \\
\hline
\end{tabular}

WC, waist circumference; HC, hip circumference; WHR, waist-to-hip ratio; WSR, waist-to-stature ratio; TUA, total upper-arm area; UMA, upper-arm muscle area; UFA, upper-arm fat area; AFI, arm fat index; GLY, blood glucose; TC, total cholesterol.

Note on Tukey's test between sub-samples: Roma $v$. Moroccans in weight, arm circumference and TUA $(P<0.05)$; Roma $v$. Kosovars in WC and HC $(P<0.05)$.

Other comparisons between groups were not significant.

†Computations were performed using normalized values.

highest values of TUA, UMA, UFA and AFI. They also had the highest values of GLY and the lowest ones of TC.

\section{Associations of anthropometric variables and blood parameters}

Table 3 shows the coefficients of correlation between anthropometric variables and blood parameters in males and females. In males, the reciprocal of GLY showed significant negative correlations with almost all anthropometric variables (except for height). TC and Log(TAG) showed significant positive correlations with weight, BMI, WC, WHR and WSR. Moreover, Log(TAG) was positively correlated to arm and hip circumferences, UMA and negatively correlated to height.

Also in females there were negative correlations of the reciprocal of GLY with almost all anthropometric variables 
Table 3 Correlations between anthropometric measures and GLY, TAG (after their normalization) and TC; multi-ethnic sample of adult immigrants, Bologna, northern Italy

\begin{tabular}{|c|c|c|c|c|c|c|}
\hline \multirow[b]{2}{*}{ Characteristic } & \multicolumn{3}{|c|}{ Males ( $n$ 229) } & \multicolumn{3}{|c|}{ Females ( $n$ 72) } \\
\hline & 1/GLY & TC & $\log (T A G)$ & 1/GLY & $\mathrm{TC}$ & $\log (T A G)$ \\
\hline Height (cm) & 0.1025 & -0.1413 & $-0.1679^{*}$ & $0.3803^{*}$ & -0.2676 & $-0.3153^{\star}$ \\
\hline Weight (kg) & $-0.2365^{\star *}$ & $0.1955^{*}$ & $0.2445^{\star \star}$ & -0.0326 & -0.0189 & -0.0227 \\
\hline BMI $\left(\mathrm{kg} / \mathrm{m}^{2}\right)$ & $-0.2863^{\star \star *}$ & $0.2561^{\star \star}$ & $0.3146^{\star \star \star}$ & -0.1915 & 0.1003 & 0.1146 \\
\hline Arm circumference $(\mathrm{cm})$ & $-0.1903^{\star}$ & 0.1308 & $0.1657^{*}$ & -0.2166 & 0.0750 & 0.1530 \\
\hline WC (cm) & $-0.3560^{\star \star \star}$ & $0.3374^{\star *}$ & $0.3330^{\star \star \star}$ & -0.1705 & 0.0664 & 0.2924 \\
\hline $\mathrm{HC}(\mathrm{cm})$ & $-0.2513^{\star *}$ & 0.1234 & $0.2831^{\star \star}$ & -0.1916 & 0.1289 & 0.0757 \\
\hline WHR & $-0.4149^{\star \star \star}$ & $0.4586^{\star \star *}$ & $0.3413^{\star * \star}$ & -0.0792 & -0.0603 & $0.3468^{*}$ \\
\hline WSR & $-0.3440^{\star \star \star}$ & $0.3787^{\star \star \star}$ & $0.3341^{\star \star \star}$ & -0.2550 & 0.1555 & $0.3340^{\star}$ \\
\hline Triceps skinfold (mm) & $-0.2473^{\star *}$ & 0.1639 & 0.0462 & 0.1193 & -0.2185 & -0.0543 \\
\hline TUA $\left(\mathrm{cm}^{2}\right)$ & $-0.1856^{\star}$ & 0.1346 & 0.1535 & -0.3067 & 0.0922 & 0.1391 \\
\hline UMA $\left(\mathrm{cm}^{2}\right)$ & -0.0977 & 0.0916 & $0 \cdot 1605^{\star}$ & $-0.3975^{\star}$ & 0.2062 & 0.1764 \\
\hline UFA $\left(\mathrm{cm}^{2}\right)^{\prime}$ & $-0.2325^{\star \star}$ & 0.1549 & 0.0729 & 0.0515 & -0.1692 & -0.0141 \\
\hline AFI (\%) & $-0.2563^{\star \star}$ & 0.1718 & 0.0120 & 0.2541 & -0.2599 & -0.1191 \\
\hline
\end{tabular}

GLY, blood glucose; TC, total cholesterol; WC, waist circumference; HC, hip circumference; WHR, waist-to-hip ratio; WSR, waist-to-stature ratio; TUA, total upper-arm area; UMA, upper-arm muscle area; UFA, upper-arm fat area; AFI, arm fat index.

${ }^{\star} P<0.05 ;{ }^{\star \star} P<0.01 ;{ }^{* \star \star} P<0.001$.

Table 4 Prevalence (\%) of unhealthy indicators in males, stratified by ethnic group and overall; multi-ethnic sample of adult immigrants, Bologna, northern Italy

\begin{tabular}{|c|c|c|c|c|c|c|}
\hline & $\begin{array}{l}\text { Kosovars } \\
\text { (n } 9)\end{array}$ & $\begin{array}{l}\text { Moroccans } \\
\quad(n 134)\end{array}$ & $\begin{array}{c}\text { Senegalese } \\
(n \text { 43) }\end{array}$ & $\begin{array}{l}\text { Tunisians } \\
\quad(n 17)\end{array}$ & $\begin{array}{l}\text { Roma } \\
(n 26)\end{array}$ & $\begin{array}{l}\text { Overall } \\
(n \text { 229) }\end{array}$ \\
\hline $\mathrm{BMI} \geq 25.0 \mathrm{~kg} / \mathrm{m}^{2}$ & $62 \cdot 5$ & 52.9 & $24 \cdot 3$ & $50 \cdot 0$ & $72 \cdot 0$ & 50.2 \\
\hline$W C \geq 102 \mathrm{~cm} \dagger$ & $42 \cdot 9$ & $15 \cdot 1$ & $-\ddagger$ & $14 \cdot 3$ & 39.1 & $19 \cdot 6$ \\
\hline WHR $\geq 100$ & $-\ddagger$ & 9.6 & $-\ddagger$ & $8 \cdot 3$ & $40 \cdot 9$ & 13.9 \\
\hline WSR $\geq 0.5$ & $50 \cdot 0$ & $70 \cdot 7$ & $-\ddagger$ & $57 \cdot 1$ & 73.9 & $69 \cdot 2$ \\
\hline $\mathrm{GLY} \geq 100 \mathrm{mg} / \mathrm{dl}$ & $25 \cdot 0$ & $19 \cdot 2$ & 18.5 & $15 \cdot 4$ & 41.7 & $22 \cdot 2$ \\
\hline $\mathrm{TC} \geq 200 \mathrm{mg} / \mathrm{dl}$ & $75 \cdot 0$ & $45 \cdot 6$ & $25 \cdot 0$ & 38.5 & $69 \cdot 6$ & $46 \cdot 5$ \\
\hline $\mathrm{TAG} \geq 150 \mathrm{mg} / \mathrm{dl}$ & $42 \cdot 9$ & $30 \cdot 3$ & $11 \cdot 1$ & $30 \cdot 8$ & 58.3 & 31.8 \\
\hline
\end{tabular}

WC, waist circumference; WHR, waist-to-hip ratio; WSR, waist-to-stature ratio; GLY, blood glucose; TC, total cholesterol.

†Data already published (Gualdi-Russo et al. ${ }^{(19)}$ )

$\ddagger$ Data unavailable.

(the exceptions being height, triceps skinfold, UFA and AFI). Unlike males, these correlations were significant only between GLY and height or UMA (probably due to the small number of subjects). $\log (\mathrm{TAG})$ was significantly correlated to height, WHR and WSR. There were no significant relationships between TC and the anthropometric variables.

\section{Prevalence of adiposity indices and blood parameters above the cut-off}

Based on cut-off values (Tables 4 and 5), Roma had the highest prevalence of overweight/obesity among male groups (overweight: $40.0 \%$, obesity: $32.0 \%$ ) followed by Kosovars (overweight: $25.0 \%$, obesity: $37.5 \%$ ), Moroccans (overweight: $45 \cdot 5 \%$, obesity: $7.4 \%$ ) and Tunisians (overweight: $35.7 \%$, obesity: $14.3 \%$ ). Senegalese were the lightest in general and had the lowest prevalence of overweight (21.6\%) and obesity (2.7\%). In women the ethnic groups showed a different trend in BMI: the prevalence of obesity was highest among Kosovars (overweight: $38.5 \%$, obesity: $38.5 \%$ ) followed by Moroccans (overweight: $50.0 \%$, obesity: $25.0 \%$ ) and Roma (overweight: $33.3 \%$, obesity: $12 \cdot 1 \%)$. The prevalence of abdominal fatness, according to
Table 5 Prevalence (\%) of unhealthy indicators in females, stratified by ethnic group and overall; multi-ethnic sample of adult immigrants, Bologna, northern Italy

\begin{tabular}{|c|c|c|c|c|}
\hline & $\begin{array}{c}\text { Kosovars } \\
(n 16)\end{array}$ & $\begin{array}{l}\text { Moroccans } \\
\quad(n 21)\end{array}$ & $\begin{array}{l}\text { Roma } \\
(n \text { 35) }\end{array}$ & $\begin{array}{c}\text { Overall } \\
(n 72)\end{array}$ \\
\hline $\mathrm{BMI} \geq 25.0 \mathrm{~kg} / \mathrm{m}^{2}$ & $77 \cdot 0$ & $75 \cdot 0$ & $45 \cdot 4$ & $58 \cdot 6$ \\
\hline$W C \geq 88 \mathrm{~cm} \dagger$ & $83 \cdot 3$ & 54.5 & $32 \cdot 1$ & $44 \cdot 4$ \\
\hline WHR $\geq 0.85$ & $66 \cdot 7$ & $60 \cdot 0$ & 39.3 & $47 \cdot 7$ \\
\hline$W S R \geq 0.5$ & $100 \cdot 0$ & $70 \cdot 0$ & $42 \cdot 9$ & $56 \cdot 8$ \\
\hline $\mathrm{GLY} \geq 100 \mathrm{mg} / \mathrm{dl}$ & $7 \cdot 1$ & 11.8 & 3.2 & 6.5 \\
\hline $\mathrm{TC} \geq 200 \mathrm{mg} / \mathrm{dl}$ & $23 \cdot 1$ & $17 \cdot 6$ & $46 \cdot 7$ & 33.3 \\
\hline $\mathrm{TAG} \geq 150 \mathrm{mg} / \mathrm{dl}$ & $23 \cdot 1$ & 23.5 & $40 \cdot 0$ & 31.7 \\
\hline
\end{tabular}

WC, waist circumference; WHR, waist-to-hip ratio; WSR, waist-to-stature ratio; GLY, blood glucose; TC, total cholesterol.

†Data already published (Gualdi-Russo et al. ${ }^{\left({ }^{19}\right)}$ ).

WHR and WSR, was highest in male Roma and in female Kosovars (the WC data reported in the tables were discussed previously $\left.{ }^{(19)}\right)$. With regard to the blood indicators, male Roma showed the highest prevalence of participants above the cut-off values for GLY and TAG, and were exceeded only by Kosovars for TC. Among females, Roma had the highest prevalence for TC and TAG, and Moroccans for GLY. 
Table 6 Coefficients from regression equations for estimating blood traits (GLY, TC and TAG) from selected anthropometric parameters (WC, WHR and WSR) by ethnicity in males; multi-ethnic sample of adult immigrants, Bologna, northern Italy

\begin{tabular}{|c|c|c|c|c|c|c|c|c|}
\hline & \multicolumn{4}{|c|}{ Immigrants (n 203) } & \multicolumn{4}{|c|}{ Roma (n 26) } \\
\hline & a & $b$ & $R^{2}$ & $P$ & a & $b$ & $R^{2}$ & $P$ \\
\hline \multicolumn{9}{|l|}{$1 / G L Y$} \\
\hline WC & 0.0151 & -0.00005 & 0.0876 & 0.0024 & 0.01648 & -0.00006 & 0.2452 & 0.0191 \\
\hline WHR & 0.0202 & -0.00988 & 0.1316 & 0.0003 & 0.02429 & -0.01426 & 0.2918 & 0.0115 \\
\hline WSR & 0.0143 & -0.00617 & 0.0591 & 0.0143 & 0.01656 & -0.01056 & 0.2750 & 0.0122 \\
\hline \multicolumn{9}{|l|}{ TC } \\
\hline WC & $126 \cdot 3136$ & 0.7374 & 0.0609 & 0.0491 & 112.527 & 1.1008 & 0.1741 & 0.0534 \\
\hline WHR & 24.3709 & $181 \cdot 7017$ & 0.1118 & 0.0096 & -82.579 & $308 \cdot 1241$ & 0.3174 & 0.0078 \\
\hline WSR & 119.9356 & 137.6499 & 0.0668 & 0.0426 & 113.076 & 182.5321 & 0.1891 & 0.0431 \\
\hline \multicolumn{9}{|c|}{$\log (T A G)$} \\
\hline WC & 1.5823 & 0.0052 & 0.0588 & 0.0140 & 1.5987 & 0.0064 & 0.1174 & 0.1095 \\
\hline WHR & 1.2294 & 0.8720 & 0.0585 & 0.0175 & 1.0046 & $1 \cdot 2507$ & 0.0991 & 0.1536 \\
\hline WSR & 1.6369 & 0.7883 & 0.0439 & 0.0356 & 1.5526 & 1.1542 & 0.1476 & 0.0703 \\
\hline
\end{tabular}

GLY, blood glucose; TC, total cholesterol; WC, waist circumference; WHR, waist-to-hip ratio; WSR, waist-to-stature ratio; $a, y$-intercept of the line; $b$, slope of the line; $R^{2}$, coefficient of determination; $P$, level of probability.

\section{Linear relationships between anthropometric variables and blood parameters in Roma $\mathrm{v}$. immigrants}

Given the highly significant correlations in men between the three blood parameters and anthropometric variables (in particular WC, WHR and WSR), a regression analysis was performed on the immigrant sample and separately in the Roma, the group with the highest risk factors according to the present and previous data ${ }^{(19)}$ (Table 6). The Roma sample exhibited a particular slope of the regression line compared with that of the immigrant sample: a mean increase in TC of $0.74 \mathrm{mg} / \mathrm{dl}$ for immigrants and of $1.10 \mathrm{mg} / \mathrm{dl}$ for Roma per $\mathrm{cm}$ of increase in WC; a mean increase in $\log (\mathrm{TAG})$ of 0.005 for immigrants and 0.006 for Roma per $\mathrm{cm}$ of increase in $\mathrm{WC}$; a mean decrease in $1 / \mathrm{GLY}$ of $0.00005(\mathrm{mg} / \mathrm{dl})^{-1}$ for immigrants and 0.00006 $(\mathrm{mg} / \mathrm{dl})^{-1}$ for Roma per $\mathrm{cm}$ of increase in WC. The mean increase in TC was $181.7 \mathrm{mg} / \mathrm{dl}$ for immigrants and $308.1 \mathrm{mg} / \mathrm{dl}$ for Roma per unit increase in WHR. The mean increase in Log(TAG) was 0.872 for immigrants and 1.251 for Roma per unit increase in WHR. The mean decrease in $1 / \mathrm{GLY}$ was $0.00989(\mathrm{mg} / \mathrm{dl})^{-1}$ for immigrants and 0.01426 $(\mathrm{mg} / \mathrm{dl})^{-1}$ for Roma per unit increase in WHR. The mean increase in TC was $137.6 \mathrm{mg} / \mathrm{dl}$ for immigrants and $182.5 \mathrm{mg} / \mathrm{dl}$ for Roma per unit increase in WSR. The mean increase in $\log (\mathrm{TAG})$ was 0.788 for immigrants and 1.154 for Roma per unit increase in WSR. The mean decrease in 1/GLY was $0.00617(\mathrm{mg} / \mathrm{dl})^{-1}$ for immigrants and 0.01056 $(\mathrm{mg} / \mathrm{dl})^{-1}$ for Roma per unit increase in WSR.

\section{Discussion}

The present study provides novel information indicating that glycaemic status and lipid profile are significantly associated with simple anthropometric variables in the multi-ethnic sample of immigrants and Roma examined in Italy. Previous indications of relationships of some anthropometric characteristics with health risk factors were reported for native subjects of different countries ${ }^{(15,25)}$. In immigrants of different ethnic groups (Chinese, South Asians, African-Americans, Mexican-Americans and Japanese), it was found that cardiovascular risk markers had different relevance according to various factors (smoking, alcohol consumption, etc.). The migration process and subsequent lifestyle changes generally lead to a higher prevalence of metabolic syndrome in migrants than in natives of the host country ${ }^{(9,26)}$. There is evidence that non-Western migrants are likely to acquire the chronic disease patterns of the country to which they migrate according to Gushulak and MacPherson ${ }^{(27)}$. In some cases, migrants and their offspring have higher rates of mortality and morbidity linked to CVD than the host population $^{(12,28)}$.

This kind of research is still very limited in Italy and requires more studies in the different ethnic minority groups. In the present study Roma males showed the highest mean values of BMI, WC, WSR and WHR. In addition, it is possible to note that for each blood parameter analysed, the Roma was the ethnic group with the worst values in regard to the healthy ranges advised by the American Heart Association. Differences between Roma and other ethnic groups were significant in height (in comparison with Senegalese, Tunisians and Moroccans), BMI (in comparison with Senegalese and Moroccans), WSR (in comparison with Tunisians and Moroccans), WHR (in comparison with Kosovars) and TAG (in comparison with Senegalese). In males, Roma had the highest prevalence of unhealthy values of blood parameters and anthropometric indices related to general (BMI) and central obesity (WHR, WSR). Kosovars had the highest prevalence of WC and TC values exceeding the cut-off. They also had high mean values of BMI and parameters connected with adiposity such as triceps skinfold and AFI. Moroccans had the second highest prevalence of overweight/obesity and central obesity (WSR). 
A different trend was present in females. Roma showed the lowest mean values of BMI and centrality indices, e.g. the lowest prevalence of general and central obesity. In contrast they had the highest mean TC and TAG values, e.g. the highest prevalence of TC and TAG values exceeding the cut-off. Kosovars presented the highest prevalence of general and central obesity, but the lowest prevalence of unhealthy values for GLY and TAG. Differences between Roma and other ethnic groups were significant in height, arm circumference and TUA (in comparison with Moroccans), WC and HC (in comparison with Kosovars).

The obvious limitation of the present study is the small ethnic sub-samples (especially for females) and it is possible some of the relationships that failed to reach significance did not have sufficient power. One strength of the study is that the indices were derived from actual anthropometric measures performed by specialized personnel with standardized training. Beyond overall and abdominal obesity there are a number of other cardiometabolic risk factors, such as hypertension (analysed previously), which were not taken into account in the present assessment of health risk. However, to our knowledge the current study is the first in Italy to present a systematic analysis of relationships between adiposity indices and blood parameters in minority groups. Another limitation of the study is that possible causes of health risk such as eating habits and physical activity are only hypothesized in our multi-ethnic sample. In addition, no information on possible strenuous occupational activity of immigrants was available. Finally, it is not possible to establish a precise causality, as it is a cross-sectional study.

The results of the current study highlight that Roma males (as observed also in a Slovak study on children and adolescents by Huiová et l. $^{(29)}$ ) present the highest health risk and that this risk increases more rapidly with increasing obesity than in the immigrant sample. Although published research on the health of the Roma population is sparse, these findings confirm our previous results ${ }^{(19)}$. They are also in accordance with studies by Krajcovicova-Kudlackova et al. ${ }^{(30)}$ and Hidvegi et al. ${ }^{(31)}$ reporting higher values of cholesterolaemia and obesity in Roma than in the majority population of Slovakia and their high prevalence of metabolic syndrome and glucose intolerance in Hungary. The health status of the Roma was worse than that of the non-Roma population in both the Czech and Slovak Republics ${ }^{(32)}$, with a higher prevalence of CVD predictors also in Roma children and adolescents ${ }^{(29)}$.

The Roma, isolated and persecuted throughout history, are still forced to live on the margins of society, thus maintaining and developing their own identity. It can be assumed that the maintenance of a traditional way of life within closed communities together with a shift to a more sedentary lifestyle and unhealthy eating patterns (transition to a Westernized lifestyle according to Poveda et $a l .{ }^{(33)}$ ) have been decisive in the increased health risk of this group in Italy. It is also likely that their worse access to health services is partially responsible for their poorer health in comparison to non-Roma ${ }^{(34)}$. The educational level of the Roma is low: many Roma children living in Italy, whose parents are themselves illiterate, do not attend school regularly ${ }^{(35)}$. Their poor social conditions and low educational level surely have negative effects on their health. Chronic diseases caused by stress, inadequate nutrition and poor housing conditions were five to twenty times more frequent than in the general population in a study carried out in Bosnia and Herzegovina ${ }^{(36)}$. In addition to these numerous cultural (lifestyle) factors contributing to their increased risk of CVD, they are genetically predisposed to obesity ${ }^{(37)}$ and abdominal fat distribution, as recently provided by quantitative genetic methods applied to anthropometric characteristics ${ }^{(33)}$. The same unhealthy values of lipids and glycaemia observed in Roma females in our study, coupled with low values of adiposity indices, could be indicative of a genetic influence that deserves to be investigated and understood.

Particular attention should also be given to other ethnic groups at risk, such as Kosovars and Moroccans. Published research on obesity and CVD in Kosovars is very scarce. According to our previous study ${ }^{(19)}$, Kosovar males showed the highest prevalence of hypertension among the examined multi-ethnic sample. Moreover, it was reported that they had the least amount of physical activity among adult refugees in the USA ${ }^{(38)}$. According to Ujcic-Voortman et $a l^{(10)}$, Moroccan immigrants in Europe have an increased risk of diabetes compared with the indigenous European population, probably in relation to their higher rates of obesity. These results are explained as due to the changes accompanying migration since the prevalence of overweight and obesity, both strong risk factors for diabetes, was much higher among Moroccans living in Europe than among those living in Morocco ${ }^{(39,40)}$.

According to the second aim of our study, we attempted to identify an anthropometric indicator with the best discrimination power for the examined blood disorders. The results suggest that WHR is slightly better than WC and WSR, although all three anthropometric parameters can be very useful in predicting an unhealthy situation such as lipid disorders or hyperglycaemia in the blood of male immigrants and Roma. These observations, confirming previously reported findings of a higher predictive value of central obesity parameters than of BMI for CVD risks $^{(8,41,42)}$, highlight for the first time in a multi-ethnic sample of immigrants living in Italy the capabilities of a simple anthropometric method for rapid preliminary screening in the case of high immigration levels, even if the adoption of one parameter over another is difficult to suggest on the basis of the available results and it may be not adequate for females.

Since the number of migrants is expected to rise in the near future, it is of crucial importance to develop 
interventions targeting ethnic minority groups in order to prevent the development of health risks and working towards a common immigration policy in Europe ${ }^{(43)}$. Further exploration of ethnic-specific differences may lead to more effective strategies for prevention and management of obesity, with particular attention to central obesity.

\section{Conclusions}

Despite some limitations, our findings provide evidence of significant correlations of some anthropometric parameters with GLY, TC and TAG in male immigrants and Roma. The prevalence of general and central obesity and dyslipidaemia was higher in men than in women. Different levels of CVD risk were found in the examined ethnic groups, with particularly high ones among Roma males. WHR, WC and WSR provide a better tool to discriminate obesity related to CVD risk than other indicators such as BMI, confirming that the latter overall obesity index is less appropriate for the prediction of cardiovascular events than central obesity indices. Our findings support previous claims that central obesity indices, WHR in particular, can be used as a rapid, non-invasive method for health screening of large samples of subjects.

Finally, we believe that there is an urgent and general need for further research into the health risks of migrants and Roma people, particularly regarding non-communicable diseases. Culturally appropriate diet and lifestyle intervention programmes should be implemented in immigrants and nomads, also by means of linguistic mediators, so that the importance of an active lifestyle and healthy eating can truly be understood.

\section{Acknowledgements}

Acknowledgements: The authors are very grateful to the reviewers for their careful corrections, advice and suggestions. They would also like to thank Alessandro Zironi for his cooperation and assistance during the data collection. Financial support: Grants and other financial support for this study were provided by the Italian Health Ministry and by the European Union Seventh Framework Programme (FP7/2007-2013, grant 260715). The funders had no role in the design, analysis or writing of this article. Conflict of interest: None. Authorship: E.G.-R. drafted the paper and was involved in its conception, design and analysis. G.V.D. contributed to the design of the original study. L.Z. performed the statistical analyses. L.Z. and S.T. took part in drafting the paper. E.G.-R., L.Z. and S.T. contributed to the critical revision of the paper. All the authors have read and approved the contents of the submitted paper. Ethics of buman subject participation: The project was approved by the Italian Ministry of Health.

\section{References}

1. Valsamakis G, Chetty R, Anwar A et al. (2004) Association of simple anthropometric measures of obesity with visceral fat and the metabolic syndrome in male Caucasian and Indo-Asian subjects. Diabet Med 21, 1339-1345.

2. Petersson H, Daryani A \& Risérus U (2007) Sagittal abdominal diameter as a marker of inflammation and insulin resistance among immigrant women from the Middle East and native Swedish women: a cross sectional study. Cardiovasc Diabetol 6, 10.

3. Onisto N, Teofoli F, Zaccagni L et al. (2009) Anthropometric traits and aging: a cross-sectional survey in diabetic elderly women. Arch Gerontol Geriatr 48, 197-200.

4. Steinbrecher A, Heak S, Morimoto Y et al. (2012) Various adiposity measures show similar positive associations with type 2 diabetes in Caucasians, native Hawaiians, and Japanese Americans: the Multiethnic Cohort. Asia Pac J Public Health (Epublication ahead of print version).

5. Agyemang C, van Valkengoed IG, van den Born BJ et al. (2012) Heterogeneity in sex differences in the metabolic syndrome in Dutch white, Surinamese African and South Asian populations. Diabet Med 29, 1159-1164.

6. Misra A \& Khurana L (2011) Obesity-related noncommunicable diseases: South Asians vs White Caucasians. Int J Obes (Lond) 35, 167-187.

7. Biggs ML, Mukamal KJ, Luchsinger JA et al. (2010) Association between adiposity in midlife and older age and risk of diabetes in older adults. JAMA 303, 2504-2512.

8. Ashwell M, Gunn P \& Gibson S (2012) Waist-to-height ratio is a better screening tool than waist circumference and BMI for adult cardiometabolic risk factors: systematic review and meta-analysis. Obes Rev 13, 275-286.

9. Kolt GS, Schofield GM, Rush EC et al. (2007) Body fatness, physical activity, and nutritional behaviours in Asian Indian immigrants to New Zealand. Asia Pac J Clin Nutr 16, 663-670.

10. Ujcic-Voortman JK, Schram MT, Jacobs-van der Bruggen MA et al. (2009) Diabetes prevalence and risk factors among ethnic minorities. Eur J Public Health 19, 511-515.

11. Sorensen MV, Snodgrass JJ, Leonard WR et al. (2005) Health consequences of postsocialist transition: dietary and lifestyle determinants of plasma lipids in Yakutia. Am J Hum Biol 17, 576-592.

12. Gilbert PA \& Khokhar S (2008) Changing dietary habits of ethnic groups in Europe and implications for health. Nutr Rev 66, 203-215.

13. Méjean C, Traissac P, Eymard-Duvernay S et al. (2009) Influence of acculturation among Tunisian migrants in France and their past/present exposure to the home country on diet and physical activity. Public Health Nutr 12, 832-841.

14. Råberg $\mathrm{M}$, Kumar $\mathrm{B}$, Holmboe-Ottesen $\mathrm{G}$ et al. (2010) Overweight and weight dissatisfaction related to socioeconomic position, integration and dietary indicators among South Asian immigrants in Oslo. Public Health Nutr 13, 695-703.

15. Razak F, Anand S, Vuksan V et al. (2005) Ethnic differences in the relationships between obesity and glucose-metabolic abnormalities: a cross-sectional population-based study. Int J Obes Relat Metab Disord 29, 656-667.

16. Zakeri H, Frohlich JJ \& Lear SA (2006) Relation of anthropometric parameters to the functional assessment of HDL particle size in three ethnic cohorts. Asia Pac J Clin Nutr 15, 300-306.

17. Anthony D, Baggott R, Tanner J et al. (2012) Community Interventions for Health $(\mathrm{CIH})$ collaboration. Health, lifestyle, belief and knowledge differences between two ethnic groups with specific reference to tobacco, diet and physical activity. J Adv Nurs 68, 2496-2503. 
18. ISTAT (2011) La popolazione straniera residente in Italia. http://www.istat.it/it/archivio/39726 (accessed June 2013).

19. Gualdi-Russo E, Zironi A, Dallari GV et al. (2009) Migration and health in Italy: a multi-ethnic adult sample.J Travel Med 16, 88-95.

20. Lohman TG, Roche AF \& Martorell R (1997) Manuale di riferimento per la standardizzazione antropometrica. Milan: EDRA Medical Publishing \& New Media.

21. Frisancho AR (2008) Anthropometric Standards: An Interactive Nutritional Reference of Body Size and Body Composition for Children and Adults. Ann Arbor, MI: The University of Michigan Press.

22. James PT, Leach R, Kalamara E et al. (2001) The worldwide obesity epidemic. Obes Res 9, Suppl. 4, 228S-233S.

23. Lean MJ \& Han TS (2002) Waist worries. Am J Clin Nutr 76, 699-700.

24. National Cholesterol Education Program (NCEP) Expert Panel on Detection, Evaluation, and Treatment of High Blood Cholesterol in Adults (Adult Treatment Panel III) (2002) Third Report of the National Cholesterol Education Program (NCEP) Expert Panel on Detection, Evaluation, and Treatment of High Blood Cholesterol in Adults (Adult Treatment Panel III) final report. Circulation 106, 3143-3421.

25. Gostynski M, Gutzwiller F, Kuulasmaa $\mathrm{K}$ et al.; WHO MONICA Project (2004) Analysis of the relationship between total cholesterol, age, body mass index among males and females in the WHO MONICA Project. Int $J$ Obes Relat Metab Disord 28, 1082-1090.

26. Cleland SJ \& Sattar N (2005) Impact of ethnicity on metabolic disturbance, vascular dysfunction and atherothrombotic cardiovascular disease. Diabetes Obes Metab 7 , 463-470.

27. Gushulak BD \& MacPherson DW (2006) The basic principles of migration health: population mobility and gaps in disease prevalence. Emerg Themes Epidemiol 3, 3.

28. Dekker LH, Snijder MB, Beukers MH et al. (2011) A prospective cohort study of dietary patterns of non-western migrants in the Netherlands in relation to risk factors for cardiovascular diseases: HELIUS-Dietary Patterns. BMC Public Health 11, 441.

29. Hujová Z, Alberty R, Ahlers I et al. (2010) Cardiovascular risk predictors in central Slovakian Roma children and adolescents: regional differences. Cent Eur J Public Health 18, 139-144.
30. Krajcovicova-Kudlackova M, Blazicek $\mathrm{P}$, Ginter E et al. (2002) Insulin levels in Gipsy minority. Bratisl Lek Listy 103, 459-461.

31. Hidvegi T, Hetyesi K, Biro L et al. (2012) Screening for metabolic syndrome within a minority ethnic group (adult Gypsy people) in Hungary. Bratisl Lek Listy 113, 721-724.

32. Koupilová I, Epstein H, Holcík J et al. (2001) Health needs of the Roma population in the Czech and Slovak Republics. Soc Sci Med 53, 1191-1204.

33. Poveda A, Ibáñez ME \& Rebato E (2012) Heritability and genetic correlations of obesity-related phenotypes among Roma people. Ann Hum Biol 39, 183-189.

34. Jarcuska P, Bobakova D, Uhrin J et al. (2013) Are barriers in accessing health services in the Roma population associated with worse health status among Roma? Int J Public Health 58, $427-434$.

35. Baldin S \& Zago M (2011) Il mosaico Rom. Specificità culturali e governante multilivello. Milan: Franco Angeli ed.

36. Sivic S, Huremovic A \& Djerzic H (2013) Social exclusion as a determining health factor of the Roma population. Med Arb 67, 60-62.

37. Zeljko HM, Škarić-Jurić T, Narančić NS et al. (2011) E2 allele of the apolipoprotein $\mathrm{E}$ gene polymorphism is predictive for obesity status in Roma minority population of Croatia. Lipids Health Dis 10, 9.

38. Barnes DM, Harrison C \& Heneghan R (2004) Health risk and promotion behaviors in refugee populations. $J$ Health Care Poor Underserved 15, 347-356.

39. Satman I, Yilmaz T, Sengul A et al. (2002) Population-based study of diabetes and risk characteristics in Turkey: results of the Turkish diabetes epidemiology study (TURDEP). Diabetes Care 25, 1551-1556.

40. Toselli S, Galletti L, Pazzaglia S et al. (2008) Two-stage study (1990-2002) of North African immigrants in Italy. Homo 59, 439-452.

41. Hsieh SD \& Muto T (2006) Metabolic syndrome in Japanese men and women with special reference to the anthropometric criteria for the assessment of obesity: proposal to use the waist-to-height ratio. Prev Med 42, 135-139.

42. Schneider HJ, Glaesmer H, Klotsche J et al. (2007) Accuracy of anthropometric indicators of obesity to predict cardiovascular risk. J Clin Endocrinol Metab 92, 589-594.

43. Hollings J, Samuilova M \& Petrova-Benedict R (2012) Health, migration and border management: analysis and capacitybuilding at Europe's borders. Int J Public Health 57, 363-369. 